\title{
SALVAGEABILITY OF GIANT HYDRONEPHROSIS NON-VISUALISED ON IVU
}

\author{
Rajaram Thiagarajan', Balaji A. R², Ayesha Shaheen ${ }^{3}$, Venkatesh Ulaganathan ${ }^{4}$, Sudhakar ${ }^{5}$ \\ ${ }_{1}^{1}$ Professor and HOD, Department of Urology, Government Stanley Medical College. \\ ${ }^{2}$ Assistant Professor, Department of Urology, Government Stanley Medical College.

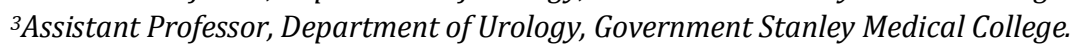 \\ 4 Post Graduate, Department of Urology, Government Stanley Medical College. \\ 5 Post Graduate, Department of Urology, Government Stanley Medical College.
}

\section{ABSTRACT}

The presence of over $1000 \mathrm{~mL}$ of urine in a hydronephrotic sac in an adult is usually categorised as giant hydronephrosis. All patients with giant hydronephrosis do not have similar anatomical configuration and functional status of renal units, and therefore treatment has to be individualized in every patient. Hence, assessing the salvageability of these kidneys becomes all the more important. We have selected such cases for further evaluation with Doppler, Diuretic renogram, USG for cortical thickness and percutaneous nephrostomy. Our aim was to study all these factors and conclude which investigation gives the best assessment of salvageability.

\section{AIM AND OBJECTIVE}

1. To assess the salvageability of Giant hydronephrosis, non-visualized on IVU, using percutaneous nephrostomy.

2. To compare various parameters used to estimate the recoverability of renal function.

\section{MATERIALS AND METHODS}

All patients admitted with giant hydronephrosis at Government Stanley Medical College between August 2013 and February 2016 were included in this study. Factors like Cortical thickness, Compensatory hypertrophy, Diuretic renogram, Resistive index were studied in all these cases and renal salvageability is predicted. Then percutaneous nephrostomy was done in all these cases and PCN fluid analysis was done and renal salvageability is reassessed in these cases.

\section{RESULTS}

Predicting the salvageability of chronically obstructed kidneys based on single parameter or combined parameters can be misleading. Percutaneous nephrostomy is a simple, objective assessment of the kidney function. In our study, it has altered the management in $38 \%$ of patients. Based on our analysis, it can be safely concluded that percutaneous nephrostomy is a useful tool in accurate assessment of chronically obstructed kidneys.

\section{KEYWORDS}

Hydronephrosis, Salvageability, Percutaneous Nephrostomy.

HOW TO CITE THIS ARTICLE: Thiagarajan R, Balaji AR, Shaheen A, et al. Salvageability of giant hydronephrosis non-visualised on IVU. J. Evolution Med. Dent. Sci. 2016;5(57):3913-3916, DOI: 10.14260/jemds/2016/896

\section{INTRODUCTION}

The presence of over $1000 \mathrm{~mL}$ of urine in a hydronephrotic sac in an adult is usually categorized as giant hydronephrosis. Yang et al (1958).(1) opined that the term giant hydronephrosis should be used only when the contents of the sac equalled to average daily urine output for that age. Giant hydronephrosis has also been defined as kidney that occupies an hemiabdomen, which meets or crosses the midline and which is at least 5 vertebrae in length.(2)

Congenital Ureter Pelvic Junction (UPJ) obstruction is the commonest cause of giant hydronephrosis in children and adults. Occasionally, it occurs as a result of ureterovesical junction obstruction. (3) Other causes include obstructive megaureter, ureteric atresia.(4) and obstructive ectopic ureter with or without a duplex system. These Giant hydronephrosis usually present in middle age and the main therapeutic

Financial or Other, Competing Interest: None.

Submission 13-04-2016, Peer Review 08-05-2016,

Acceptance 14-06-2016, Published 16-07-2016.

Corresponding Author:

Dr. Balaji A. R,

Assistant Professor

Department of Urology,

Government Stanley Medical College.

E-mail: uvenkatesh.mmc2k4@gmail.com

DOI: $10.14260 /$ jemds $/ 2016 / 896$ challenge is whether to go ahead with ablative or salvage procedure. All patients with giant hydronephrosis do not have similar anatomical configuration and functional status of renal units and therefore treatment has to be individualized in every patient. Hence, assessing the salvageability of these kidneys becomes all the more important.

\section{AIM AND OBJECTIVE}

The aim of the study is to assess the salvageability of giant hydronephrosis, non-visualized on IVU, using percutaneous nephrostomy and to compare various parameters used to estimate the recoverability of renal function.

\section{MATERIAL AND METHODS}

The period of study is between Aug. 2013 and February 2016 at Government Medical College. Altogether, we studied 24 patients. Of those 23 had bilateral PUJO and one pt. had PUJO. Among them 12 were male and rest were female. Patient's age ranged between 13 and 46 years. The patients are stratified based on age group into 3 groups: A. Age $<20$ years; B. Age 2040 years; C. Age $>40$ years. These patients were investigated with: 1. Haemogram, 2. Renal function test, 3. USG KUB, 4. Xray KUB, 5. IVU, 6. Doppler USG for RI, 7. Diuretic renogram. 


\section{Inclusion Criteria}

1. All giant hydronephrosis, non-visualized on IVU.

2. Patients counselled and patients giving consent for PCN were selected for study.

3. Patients who did not consent for PCN underwent nephrectomy.

\section{Percutaneous Nephrostomy}

Patient is counselled thoroughly about the procedure, the aim of PCN, duration of PCN, its complications and alternatives. Informed consent is obtained. Patient is made to lie down prone with a sandbag under ipsilateral half of abdomen. In Cefotaxime $1.0 \mathrm{gm}$ IV ATD given. Preliminary USG is done to assess the degree of dilatation, cortical thickness, depth and angulation from skin, shortest possible route. Puncture site is planned behind posterior axillary line, below and medial to the 12 th rib tip - adjusting to the shortest route. Betadine painting and draping is done. Skin and subcutaneous tissue is infiltrated with $1 \%$ lignocaine; $5 \mathrm{~mm}$ incision is made and depth increased till the muscle layers are cut. Single step $8.5 \mathrm{Fr}$ pigtail PCN catheter is used for puncture. Periodical USG guide used to track the needle path. Once collecting system is confirmed by urine in the stylet, the catheter is advanced into PCS and fixed to skin. Catheter position is confirmed by USG.

\section{Observation is made Regarding}

1. Quality of Urine-pus, turbid, clear, blood stained.

2. Quantity-drained after puncture immediately.

3. Vitals of patient checked.

Daily PCN and Urine output chart is maintained for 2 weeks.

If Quantity is Satisfactory ( $>500 \mathrm{~mL}$ ), Quality of Urine is Assessed by
a. $\mathrm{pH}$.
b. Osmolarity.
c. Specific gravity.
d. Spot Na.
e. Culture and sensitivity.

\begin{tabular}{|c|c|c|c|c|}
\hline $\begin{array}{l}\text { Sl. } \\
\text { No. }\end{array}$ & Investigations & Favourable Values. ${ }^{5}$ & Un-Favourable Values. ${ }^{6}$ & Significance \\
\hline 1. & $\mathrm{pH}$ & $<6.5$ & $>7.0$ & $\begin{array}{l}\text { 1. Loss of acidification function of tubule } \\
\text { 2. Rule out infection as the cause of alkaline urine }\end{array}$ \\
\hline 2. & Osmolarity & $\begin{array}{l}50-1200 \\
\mathrm{mOsm} / \mathrm{kg}\end{array}$ & $\begin{array}{c}<300 \text { esp after } \\
\text { overnight } \\
\text { dehydration }\end{array}$ & Index for concentrating ability of kidney \\
\hline 3. & Specific gravity & $1010-1030$ & Fixed 1010 & Loss of concentrating capacity \\
\hline 4. & Spot $\mathrm{Na}$ & $<40 \mathrm{mEq} / \mathrm{L}$ & $>60 \mathrm{mEq} / \mathrm{L}$ & Na leak due to defective tubular function \\
\hline 5. & Urine culture & No Growth & Growth present & Requires treatment of active infection \\
\hline
\end{tabular}

\section{Treatment Protocols. ${ }^{7}$}

1. Salvageable kidney.
a. Pyeloplasty.
b. Ureterocalicostomy.

2. Non-salvageable kidney.

a. Nephrectomy (Open Procedure).

\section{RESULTS AND ANALYSIS}

\begin{tabular}{|c|c|c|}
\hline Side & No. of Cases & No. of Cases Salvaged \\
\hline Left & 13 & \\
\hline Right & 11 & \\
\hline \multicolumn{3}{|c|}{ Table 2: Side of Obstruction } \\
\hline
\end{tabular}

\section{One Case-Bilateral PUJO}

\begin{tabular}{|c|c|c|c|c|}
\hline Category & $\begin{array}{c}\text { Age } \\
\text { Gp } \\
\text { (yrs.) }\end{array}$ & $\begin{array}{c}\text { No. of } \\
\text { Cases }\end{array}$ & $\begin{array}{c}\text { No. of } \\
\text { Cases } \\
\text { Salvaged }\end{array}$ & $\begin{array}{c}\text { \% } \\
\text { of } \\
\text { Salvageability }\end{array}$ \\
\hline A & $<20$ & 6 & 3 & $50 \%$ \\
\hline B & $\begin{array}{c}20-40 \\
\text { yrs. }\end{array}$ & 14 & 4 & $28.57 \%$ \\
\hline C & $\begin{array}{c}>40 \\
\text { yrs. }\end{array}$ & 4 & 0 & $0 \%$ \\
\hline \multicolumn{5}{|c|}{ Table 3: Age (Duration of Obstruction) } \\
and Salvageability \\
\hline
\end{tabular}

\begin{tabular}{|c|c|c|}
\hline Sex & No. of Cases & Salvaged Cases \\
\hline Male & 12 & 4 \\
\hline Female & 12 & 3 \\
\hline \multicolumn{3}{|c|}{ Table 4: Sex of the Patient } \\
\hline
\end{tabular}

\begin{tabular}{|c|c|c|c|}
\hline Category & $\begin{array}{c}\text { No. of } \\
\text { Cases }\end{array}$ & $\begin{array}{c}\text { No. of } \\
\text { Salvaged } \\
\text { Cases }\end{array}$ & $\begin{array}{c}\% \text { of } \\
\text { Salvageability }\end{array}$ \\
\hline $\begin{array}{c}\text { Opposite } \\
\text { kidney } \\
\text { Hypertrophy }\end{array}$ & 8 & 3 & $37.5 \%$ \\
\hline $\begin{array}{c}\text { Opposite } \\
\text { kidney } \\
\text { Normal }\end{array}$ & 15 & 3 & $20 \%$ \\
\hline \multicolumn{4}{|c|}{ Table 5: Compensatory Hypertrophy and Salvageability } \\
\hline
\end{tabular}

One case of Bilateral PUJO not included in this analysis

\begin{tabular}{|c|c|c|c|c|c|}
\hline RI & $\begin{array}{c}\text { No. of } \\
\text { Cases }\end{array}$ & Salvaged & $\begin{array}{c}\text { Not } \\
\text { Salvaged }\end{array}$ & $\begin{array}{c}\text { \% of } \\
\text { Salvageability }\end{array}$ & $\begin{array}{c}\text { \% not } \\
\text { Salvaged }\end{array}$ \\
\hline$<0.70$ & 7 & 1 & 6 & $14.2 \%$ & \\
\hline$>0.70$ & 17 & 6 & 11 & $35.2 \%$ & \\
\hline \multicolumn{6}{|c|}{ Table 6: Renal Resistive Index and Salvageability } \\
\hline
\end{tabular}




\begin{tabular}{|c|c|c|c|}
\hline Category & $\begin{array}{c}\text { No. of } \\
\text { Cases }\end{array}$ & $\begin{array}{c}\text { No. of } \\
\text { Cases } \\
\text { Salvaged }\end{array}$ & $\begin{array}{c}\text { \% of } \\
\text { Salvageability }\end{array}$ \\
\hline $\begin{array}{c}\text { No appreciable } \\
\text { /thin cortex }\end{array}$ & 16 & 4 & $25 \%$ \\
\hline $\begin{array}{c}\text { Cortex seen } \\
0.5-1 \mathrm{~cm}\end{array}$ & 8 & 4 & $50 \%$ \\
\hline \multicolumn{2}{|c|}{ Table 7: Cortical Thickness and Salvageability. ${ }^{8}$} \\
\hline
\end{tabular}

\begin{tabular}{|c|c|c|c|}
\hline $\begin{array}{c}\text { Split GFR } \\
\text { (mL/min) }\end{array}$ & $\begin{array}{c}\text { No. of } \\
\text { Cases }\end{array}$ & $\begin{array}{c}\text { No. of Cases } \\
\text { Salvaged }\end{array}$ & $\begin{array}{c}\text { No. of Cases not } \\
\text { Salvaged }\end{array}$ \\
\hline$<10$ & 1 & 1 & 0 \\
\hline $10-20$ & 16 & 4 & 12 \\
\hline$>20$ & 7 & 2 & 5 \\
\hline \multicolumn{2}{|r|}{ Table 8: Diuretic Renogram and Salvageability. ${ }^{\mathbf{9}}$} \\
\hline
\end{tabular}

\begin{tabular}{|c|c|}
\hline Protocol & No. of Cases \\
\hline $\mathrm{F}-20$ & 7 \\
\hline $\mathrm{F}+0$ & 17 \\
\hline \multicolumn{2}{|c|}{ Table 9: Protocol } \\
\hline
\end{tabular}

\section{Curve-Obstructed in all Cases}

\begin{tabular}{|c|c|c|}
\hline Factor & Good & Poor \\
\hline $\begin{array}{c}\text { Cortical } \\
\text { thickness }\end{array}$ & $>0.5 \mathrm{~cm}$ & No cortex \\
\hline RI & $<0.70$ & $>0.70$ \\
\hline $\begin{array}{c}\text { Opposite } \\
\text { kidney }\end{array}$ & Normal size & Increased size \\
\hline $\begin{array}{c}\text { DTPA } \\
\text { (Split GFR) }\end{array}$ & $\begin{array}{c}>20 \\
\text { (Children }>10)\end{array}$ & $\begin{array}{c}<20 \\
\text { (Children }<10)\end{array}$ \\
\hline \multicolumn{2}{|c|}{ Table 10: Pre-PCN Salvageability. ${ }^{7}$} \\
\hline
\end{tabular}

\section{PCN Fluid Analysis in Patients with Good PCN Output}

No. of cases with good output $\quad-13$

No. of cases with good quality urine $\quad-9$

No. of cases with poor quality urine $\quad-4$

No. of cases with salvageable kidneys, but

sacrificed due to secondary infection $\quad-\quad 2$

\begin{tabular}{|c|c|c|c|c|c|}
\hline \multicolumn{2}{|c|}{$\begin{array}{c}\text { Pre-PCN } \\
\text { Salvageability } \\
\text { (At least } 2 \text { Indices } \\
\text { Favourable ) }\end{array}$} & \multicolumn{2}{|c|}{$\begin{array}{c}\text { Post-PCN } \\
\text { Salvageability }\end{array}$} & \multirow{2}{*}{$\begin{array}{c}\text { Salvaged } \\
3\end{array}$} & \multirow{2}{*}{$\begin{array}{c}\text { Not Salvaged } \\
2 \text { (Pyonephrosis) }\end{array}$} \\
\hline \multirow{2}{*}{ Good } & 10 & Good & 5 & & \\
\hline & & Poor & 5 & & \\
\hline \multirow{2}{*}{ Poor } & 14 & Good & 4 & 4 & 0 \\
\hline & & Poor & 10 & & \\
\hline & $\begin{array}{l}\text { 11: Co } \\
\text { lvagec }\end{array}$ & $\begin{array}{l}\text { nparis } \\
\text { bility }\end{array}$ & $\begin{array}{l}\text { d betw } \\
\text { d the }\end{array}$ & $\begin{array}{l}\text { en Pre-PC } \\
\text { lumbers } S\end{array}$ & $\begin{array}{l}\text { N, Post-PCN } \\
\text { alvaged }\end{array}$ \\
\hline
\end{tabular}

No. of cases with favourable salvageability Pre PCN-10.

No. of cases deemed not salvageable after PCN-05.

No. of cases with unfavourable salvageability Pre PCN-14.

No. of cases deemed salvageable after PCN-4.

No. of cases in which PCN altered the treatment $-9 / 24=38 \%$.

\section{Treatment}

Nephrectomy was done in 15 cases of non-salvageable kidney and 2 cases due to pyonephrosis. Dismembered pyeloplasty was done in 5 cases. Ureterocalicostomy was done in 2 cases. Follow-Up
Period of follow-up varied from 3 months to 22 months. We followed up 7 cases of salvaged kidney, of which one was lost during follow-up. Other cases followed with 1 . Symptom score; 2. USG; 3. Renal function test; 4. Diuretic renogram for drainage; and 5. GFR. On ultrasound, all patients had residual dilatation of the collecting system. Drainage as seen in Diuretic renogram improved in all patients, GFR improved by $12 \%$ in one patient and remained almost same in other six patients.

\section{DISCUSSION}

This study population consisted of cases that show nonexcretion of contrast in IVU. Though non-visualisation on IVU may indicate critical loss of function, the renal unit cannot be branded as "Non-functional." We have selected such cases for further evaluation with Doppler, Diuretic renogram, USG for cortical thickness, DTPA and classified them either salvageable or non-salvageable. Our aim was to study all these measures of salvageability and compare them with post-percutaneous nephrostomy salvageability predictors on PCN fluid analysis mentioned in Table No. 1.

Of the 24 patients studied, the side of obstruction was not significantly related to salvageability of the kidney. Based on age groups, patients were classified into A ( $<20$ yrs.), B (20-40 yrs.) and C ( $>40$ yrs.). Most of our patients were in B category consistent with literature; most cases presented in middle age. The salvageability of the kidney was related to duration of obstruction (Age of the patient). While $50 \%$ of $\mathrm{A}$ was salvageable, none of $\mathrm{C}$ category ( $>40$ yrs.) were salvageable. Sex of the patient was found to be insignificant with regards to salvageability. Presence of compensatory hypertrophy did not significantly affect the salvageability. In our study, $37.5 \%$ of patients with compensatory hypertrophy were salvageable, while only $20 \%$ of patients with normal opposite kidneys were salvageable. Cortical thickness assessment by Ultrasonogram is highly subjective.

In our study, $25 \%$ of kidneys with no demonstrable cortex were salvageable. Good cortical thickness predicted better salvageability (50\%). Hence, cortical thickness has good positive predictive value. Resistive index had poor predictive value in our study, while $35 \%$ of kidneys with RI $>0.7$ were salvageable, kidneys with $\mathrm{RI}<0.7$-only $14 \%$ were salvageable. In our study, we found GFR assessment based on nuclear study was not correlating with salvageability. Even kidneys with GFR $>20 \mathrm{~mL} / \mathrm{min}$ - (5/7 cases) were not salvageable. This may be due to variations in protocols and technical differences (MultiInstitutional results). Based on these initial parameters, patients were roughly categorized into good and poor salvageability groups. PCN was done for all patients. Kidneys with favourable parameters - (10) - 5 of these were of poor category after PCN. Two patients with good salvageability post PCN developed pyonephrosis and underwent nephrectomy. Even in kidneys though not salvageable, PCN showed that $4 / 14$ were salvageable. Overall, PCN altered management in $38 \%$ of the patients.

There are a few study in literature that assessed the salvageability of kidney in giant hydronephrosis after insertion of PCN. Ransley et al(10) studied new-borns with PUJO and poor renal function by inserting pigtail nephrostomy tube. The patients underwent a repeat DTPA diuretic renogram and proceeded to nephrectomy, if GFR is still $<10 \%$. Upto a third of cases in this series showed recovery of function to substantiate pyeloplasty. These authors recommended that nephrectomy 
should not be performed without a period of PCN drainage. The same authors now proceed to nephrectomy if GFR $<10 \%$.

Gillenwater et al(11) the best method to assess the recoverability is to relieve the obstruction and follow the improvement in creatinine clearance. But the value of Creatinine clearance, indicative of salvageability, is not clear.

Cronan et al(12) suggested sufficient time to allow recovery. He suggested at least 8 weeks for optimization of basal renal function. Various authors suggest variable time,varying from 3-6 weeks. The quality of urine produced is equally important. Production of large volume dilute, poor quality urine does not contribute to renal functional reserve. Hence, it needs to be good quality urine to indicate salvageability.

We found all the regular parameters like cortical thickness, compensatory hypertrophy, diuretic renogram, and resistive index are not without pitfalls. Predicting the salvageability of chronically obstructed kidneys based on single parameter or combined parameters can be misleading. However, since performing two DTPA is financially not viable we resorted to post PCN fluid analysis predictors of salvageability (Table 1).

Percutaneous nephrostomy is a simple, objective assessment of the kidney function. In our study, it has altered the management in $38 \%$ of patients. Based on our analysis, it can be safely concluded that Percutaneous nephrostomy is a useful tool in accurate assessment of chronically obstructed kidneys.

\section{CONCLUSION}

We favour percutaneous nephrostomy if patient is febrile and/or serum creatinine is elevated or IVU shows nonvisualized unit or pelvicalyceal system is not well delineated. Further, based upon overall functional status, ablation of unit or reconstructive surgery is planned. The type of reconstruction is individualized as per anatomical configuration demonstrated on antegrade study or IVU.

\section{REFERENCES}

1. Yang W, Shen S, Wa C. Hydronephrosis and giant hydronephrosis. Chinese Med J 1958;77(3):257-9.

2. Crocks KK, Hendren WH, Pfister RC. Giant hydronephrosis in children. J Paediatr Surg 1979;14(6):844-50.

3. Haque J, Mukherjee B, Prasad GR, et al. Ureterovesical junction obstruction presenting as giant hydronephrosis. Indian J Paediatr 1985;52(1):107-9.

4. Slater GS. Ureteral atresia producing giant hydroureter. J Urol 1957;78(2):135-7.

5. Eddy AA. Molecular insights into renal interstitial fibrosis. J Am Soc Nephrol 1996;7(12):2495-508.

6. Talner, Chen MT, Chou YH. Specific causes of obstruction. J Urol 1968;100(2):100-20.

7. Sheehan HL, Davis JC. Experimental hydronephrosis. Arch Pathol 1959;68(2):185-225.

8. Strong, Pirincci N, Karaman MI. Plastic studies in abnormal renal architecture. J Urol 1957;78:135-7.

9. Lagefoged 0, Djurhuus JC. Morphology of the upper urinary tract in experimental hydronephrosis in pigs. Acta Chir Scand Suppl 1976;472:29-35.

10. Ransley, Sauter TW, De Petriconi R. Post natal management of antenatally detected hydronephrosis. Eur Urol 1987;13:42.

11. Gillenwater, Chapple CR, Johnson AG. Pathophysiology of urinary obstruction. J Paediatr Surg 1979;14:844..

12. Cronan, Milewski JB, Borkowski A, et al. Calycocystostomy in the treatment of giant hydronephrosis. Eur Urol 1987;13:42. 